\title{
PRATICANDO A TRÍADE ENSINO-PESQUISA-EXTENSÃO NO ESTÁGIO SUPERVISIONADO DE LICENCIATURA EM CIÊNCIAS BIOLÓGICAS
}

\author{
PRACTICING THE TRIAD TEACHING-RESEARCH- EXTENSION IN \\ SUPERVISED INTERNSHIP OF LICENTIATESHIP IN BIOLOGICAL SCIENCES
}

Lilliane Miranda Freitas ${ }^{1}$

Rafaela Lebrego Araújo ${ }^{2}$

\section{RESUMO}

Neste trabalho, relatamos uma experiência de ensino baseada na tríade ensino-pesquisaextensão, ocorrida na disciplina de Estágio Supervisionado do curso de Licenciatura em Ciências Biológicas. Nessa experiência, os graduandos fizeram uma transposição dos conhecimentos científicos produzidos em seus trabalhos de conclusão de curso para saberes do currículo escolar da educação básica. Analisamos, neste artigo, os registros de impressão produzidos pelos licenciandos, após a realização das ações pedagógicas. Discutimos através dos relatos como o conhecimento que é construído e reconstruído nas pesquisas acadêmicas pode contribuir diretamente na melhoria da qualidade do Ensino de Ciências, através da alfabetização científica,e, também, na formação docente dos licenciandos, através da reflexão sobre a própria prática. Assim, consideramos que, com a prática da indissociabilidade ensinopesquisa-extensão,haverá mais retorno para as pesquisas acadêmicas e também para a comunidade escolar, gerando alterações significativas das práticas educativas nas escolas.

Palavras-chave: Estágio supervisionado, Pesquisa acadêmica, Ensino-pesquisa-extensão, Prática reflexiva.

\begin{abstract}
In this paper we report an educational experience based on the triad teaching-researchextension occurred in the supervised internship in licentiateship in Biological Sciences. In this experiment, the students made atranspositionof the scientific knowledge producedin theircourse conclusion work to the knowledge of basic education curriculum. We analyze in this article the impressions of undergraduates after completion of pedagogical actions. We discuss, based on the reports, how the knowledgethat isconstructed and reconstructedin academic researchcan contributedirectly to the improvement of the science education quality throughscience literacyand alsoin teacher trainingof undergraduates, through the reflectionon their own practice. Therefore, we consider that, with the practice of the inseparability of teaching-research-extension, there will be more return for academic research and also for the school community, generating significant changes in educational practicesin schools.
\end{abstract}

\footnotetext{
${ }^{1}$ Mestre em Educação em Ciências pela Universidade Federal do Pará

${ }^{2}$ Mestre em Educação em Ciências pela Universidade Federal do Pará
} 
Key words: Supervised internship, Academic research,Teaching-research-extension, Reflective practice.

\section{INTRODUÇÃO}

Este trabalho trata de um dos resultados do projeto de pesquisa "Caracterização do Ensino de Ciências na região urbana do município de Bragança-Pa" ${ }^{3}$,que desenvolvemos na Universidade Federal do Pará, campus universitário de Bragança. No referido projeto, temos como objetivos, em linhas gerais, promover maior integração dos estudantes de graduação com a comunidade escolar, numa parceria que possa ir além do estágio curricular, ampliando o envolvimento dos licenciandos na iniciação à docência e na pesquisa em Educação em Ciências, além de promover a formação continuada de professores da rede estadual e municipal de ensino básico. Neste texto, porém, analisaremosapenas o primeiro objetivo, que se refereà integração dos estudantes de graduação com a comunidade escolar

Com estepropósito, relatamos, neste texto, uma experiência que surgiu no âmbito da disciplina Estágio SupervisionadoIV ${ }^{4}$, com uma turma de concluintes do curso de Licenciatura em Ciências Biológicas. Apesar de ser uma turma de concluintes, esses estudantes tiveram pouca ou nenhuma experiência em sala de aula ao longo do curso de graduação e, por isso, estavam ávidos por vivenciar a rotina escolar e, principalmente, exercer a regência em sala.

Essa lacuna é devida, em grande parte, àdisposição das disciplinas que são organizadas em blocos, isto é, elas ocorrem de maneira intensiva, uma única disciplina, de modo intensivo em algumas semanas. Assim, nosso primeiro desafio foi promover essa articulação com algumas escolas para realização dos estágios. Esse processo foi desafiador, pois as aulas nas escolas estaduais de ensino seriam retomadas apenas no início do mês de abril, uma semana após o início do estágio. Esse atraso no calendário escolar foi devido à greve dos professores da rede estadual. Dessa forma, tínhamos atarefa de fazer com que, nesse curto período, os alunos pudessem desenvolver alguns aspectos da prática docente, como o planejamentoda aula, a preparação de materiais didáticos, a seleção de conteúdos, a regência, e,além disso, a preocupação de que essa experiência fosse significativa na sua formação docente.

Ao conhecermos a turma, percebermos que os graduandos estavam, quase que na sua totalidade, muito envolvidos em suas pesquisas acadêmicas para o trabalho de conclusão de curso, até mesmo por se tratarde uma turma de concluintes. Vale ressaltar que, embora o curso fosse de licenciatura, praticamente todos os graduandos estavam desenvolvendo pesquisas em áreas de conhecimento específico, como genética, botânica, zoologia e somente dois desenvolviam na área de Educação em Ciências, mais especificamente em Educação Ambiental. Esse fatosó aumentava a distância desses licenciandos com a docência,pois acabavam por priorizar o trabalho nos laboratórios, preterindo o cunho pedagógico do curso.

Diante disso, propusemos que a turma desenvolvesse ações pedagógicas em algumas escolas do município bragantino no ensino fundamental. Para o desenvolvimento das ações pedagógicas, os licenciandos precisariam construir planos de aula com as temáticas das suas pesquisas nos trabalhos de conclusão de curso, contextualizando os saberes produzidos na academia para o âmbito da sala de aula. Essa proposta se constituiria num verdadeiro desafio, uma vez que exigiria dos estudantes transpor para uma linguagem mais próxima da sala de

\footnotetext{
${ }^{3}$ Projeto de pesquisa desenvolvido no Instituto de Estudos Costeiros/ IECOS-UFPA pelas autoras do artigo, professoras da Faculdade de Biologia deste mesmo Instituto. Órgãos que apoiaram este trabalho: FADESP e UFPA.

${ }^{4}$ Disciplina do sétimo semestre, ministrada na época pela Prof ${ }^{a}$ Rafaela Lebrego, com eventual participação e apoio da Prof ${ }^{a}$ Lilliane Freitas.
} 
aula, compreensível pelo aluno da educação básica, os saberes científicos elaborados por eles em suas pesquisas dentro dos laboratórios.

Nesse sentido, essas ações seriam também uma tentativa de tornar aplicáveis esses conhecimentos produzidos pela pesquisa laboratorial, permitindo que os licenciandos ensaiassem práticas diferenciadas em sala de aula, promovessem a alfabetização científica da comunidade escolar e ainda envolvessem os professores das escolas. Assim, as aulas foram planejadas relacionando as temáticas das pesquisas ao conteúdo do currículo das séries às quais foram destinadas e desenvolvidas as ações, caracterizando uma extensão da Universidade com algumas das escolas das comunidades de seu entorno.

Assim, a turma que era composta por trinta e seis estudantes foi dividida em nove equipes para a execução da atividade, que era a regência de uma aula temática. Essa divisão em equipes foi de acordo com a afinidade dos temas de pesquisa, pois alguns estudantes desenvolvem seus trabalhos no mesmo projeto de pesquisa ou no mesmo laboratório. As equipes realizaram as ações pedagógicas em três escolas da área urbana do município de Bragança-PA, em uma escola de uma comunidade vizinha a $7 \mathrm{~km}$ da cidade de Bragança e em uma escola do município de Augusto Corrêa, situado a15 km de Bragança.

Considerando a importância da contextualização no ensino de ciências, bem como a promoçãoda alfabetização científica, tivemos o cuidado de aproximar as temáticas da realidade das comunidades, aproximando saberes comuns e científicos, e, assim, reelaborando novos saberes.

As equipes tiveram no cronograma da disciplina dois dias para planejamento das aulas,para que se organizassem de acordo com as temáticas e, a partir disso, elegessem os conteúdos a serem ministrados, os recursos e as metodologias que seriam utilizados e qual seria o público alvo da aula. Concluído o plano de aula, as equipes tiveram dois dias de orientação com a professora da disciplina, para que fossem feitas as adequações e direcionamentos necessários e mais dois dias para preparação das aulas e confecção de materiais didáticos.As ações pedagógicas aconteceram nas escolas em quatro dias, cada aula em dias e horários diferentes, de modo que nenhuma aula ocorresse concomitantemente,permitindoqueas professoras da disciplina de estágio acompanhassem todas as aulas.

Após as atividades desenvolvidas nas escolas, os graduandos construíram o que denominamos de registro de impressão, contendo suas opiniões, sentimentos, críticas, anseios, pontos de vista, em relação ao trabalho desenvolvido. Esses registros foram elaborados individualmente, e constituem os objetos de análise deste trabalho. Esse exercício narrativo a partir dos registros possibilita ao sujeito rever seu processo de formação, favorecendo a capacidade de reflexão, a articulaçãodas experiências vivenciadas - dotando-as de significado - e reconhecer-se como sujeito de sua própria formação (CATANI et al., 1998). Os registros assim produzidos permitem um processo profundamente formativo, pois ao mesmo tempo em que o licenciando organiza as ideias para o relato, nesse caso, escrito, reconstrói sua experiência de forma reflexiva e, portanto, acaba fazendo uma autoavaliação que lhe cria novas bases de compreensão da própria prática (CUNHA, 1997).

Nessa perspectiva, o uso de registros na formação inicial docente é fundamental, uma vez que o refletir sobre as experiências de formação vivenciadas tem como objetivo constituir professores mais competentes para analisar as questões do seu cotidiano que surgem no contexto escolar - e para agir sobre elas. Dessa forma, busca-se a formação de sujeitos que não se amoldam apenas à resolução deproblemas imediatos, mas situam-se num 
horizonte mais abrangente, que põe em perspectiva a função de cada um e a da escola na sociedade em que vivemos (ALARCÃO, 2003).

Nesse sentido, a partir da análise dos registros de impressão resultantes das ações pedagógicas realizadas pelos licenciandos, passamos nas seções seguintes a discutir como essa experiência repercutiu na formação docente desses estudantes, bem como nas escolas em que foram desenvolvidas.

\section{ALIANDO ENSINO-PESQUISA-EXTENSÃO E ALFABETIZAÇÃO CIENTÍFICA}

A realização da atividade da aula temática baseada nas pesquisas acadêmicas dos licenciandos, por ter sido uma proposta inovadora no próprio curso de Ciências Biológicas em que trabalhamos, foi um grande desafio não só para nós professoras formadoras, mas principalmente para os licenciandos, que pouco ou nunca haviam sido estimulados a participar de um trabalho como este. Podemos perceber bem isso no registro de impressão de Sérgio, quando ele menciona que:

- Sabemos que para formular um trabalho desse nível para alunos de ensino fundamental seria bastante trabalhoso, mas assim mesmo topamos a ideia que seria um desafio e tanto, mesmo porque nenhum professor das disciplinas de estágio supervisionado teria proposto tal desafio (Sérgio).

Percebemos aí que atividades de caráter extensionista, como esta, ainda são, infelizmente, pouco exercidas dentro das universidades brasileiras (CHASSOT, 2003). Segundo Dias (2009), geralmente a formação acadêmica dos estudantes tem-se restringido à transmissão de ensinamentos em um único espaço: a sala de aula. Poucos são os estudantes de graduação que têm o privilégio de realizar ações de pesquisa e extensão, e na maior parte das vezes essas ações são desvinculadas da organização curricular (ensino), pois só ocorrem se o estudante estiver em laboratórios (pesquisa) ou em projetos de extensão, atividades extracurriculares, clube de ciências (extensão), mas a tríade ensino-pesquisa-extensão, entendida como indissociável, pouco acontece.

Esse isolacionismo das atividades de construção de conhecimento provoca a especialização precoce dos estudantes já na graduação, restrita aos aspectos técnicos, formais sem a contemplação de aspectos sociais e políticos, gerando uma formação descontextualizada dos problemas e demandas da sociedade contemporânea. Esse distanciamento da realidade social e principalmente escolar se mostrou como um obstáculo para os licenciandos quando tiveram que adequar os conhecimentos científicos trabalhados nas pesquisas com os conteúdos do currículo escolar, mesmo que os objetos de investigação partissem da realidade local. Certamente essa é uma das grandes dificuldades enfrentadas na formação de professores de ciências, a transposição dos saberes científicos da universidade para uma linguagem mais próxima da sala de aula da educação básica (CHASSOT, 2003).

Percebemos essa dificuldade nas falas abaixo de dois graduandos que tinham como tema de suas pesquisas, respectivamente, "A caracterização morfológica, ecológica e econômica de bivalves da família Mytillidae presente na região de Augusto Corrêa-PA" e "O efeito do meio inicial de preservação na mudança do comprimento e peso nas espécies de peixe Carnegiellastrigatahy, Phessobryconheterohab, Dusiguanodectsspilurus": 
- Foram muitos os problemas, o primeiro foi encontrar uma maneira de adaptar o conteúdo do nosso TCC, um trabalho com uma linguagem completamente científica, de uma maneira que alunos de $6^{\text {a }}$ série do ensino fundamental pudessem entender (Socorro).

- Durante a organização para a apresentação, foi bastante complicado sintetizar algumas pesquisas e adaptar alguns resultados para fácil entendimento de alunos de ensino fundamental, além de decidir os tópicos mais importantes e até a ordem em que deviam ser apresentados no intuito de facilitar o entendimento (Rodrigo).

Diante disso, um dos grandes desafios para as universidades públicas hoje está na formação de professores, em oferecer uma formação que não seja restrita aos aspectos técnicos, formais, descontextualizada dos problemas e demandas sociais, mas sim que se origine da própria realidade educacional que caracteriza o processo ensino-aprendizagem, contemplando os aspectos sociais e políticos da sociedade contemporânea (SANTOS et al., 2006).

Nesse sentido, busca-se cada vez mais a superação do paradigma da racionalidade técnica - modelo em que somente o domínio de metodologias e saberes específicos seriam suficientes para a formação docente - para a dita nova racionalização (MORIN, 2006), que discute a contextualização e complexidade, a qual não restringe a formação aos aspectos técnicos, formais, mas passaa contemplar seus aspectos sociais e políticos com o propósito de formar cidadãos capazes de olhar seu entorno de modo mais crítico e questionador. Nesse processo, a Educação Básica é composta de todos esses elementos sociais, políticos, ambientais, culturais, que a influenciam, de acordo com a realidade das comunidades nas quais as escolas estão inseridas.

Nesse contexto, as atividades de extensão e de pesquisa são vitais aos processos de ensino e de aprendizagem na formação de professores, pois proporcionam uma formação fundada na relação entre teoria e prática, contextualizada, que articule saberes científicos, pedagógicos e da experiência no desenvolvimento da prática docente e situe o licenciando quanto ao seu papel e responsabilidade social. Esse modelo de ensino baseado no tripé ensino-pesquisa-extensão é o modelo de ensino defendido e perseguido pelas universidades públicas brasileiras, pois se constitui na excelência do ensino superior, na medida em que promove produção de conhecimento em uma dada realidade social, compromisso social e possíveis transformações. A importância dessaindissociação no ensino foi percebida pelos graduandos durante a ação realizada, e pode ser verificada na seguinte fala:

- A principio imaginei que a prática não seria possível, visto que, a meu ver, o assunto a ser abordado é muito complexo. No entanto, eu estava equivocada, pois com a realização da oficina obtivemos resultados impressionantes. A prática deve seguir com todas as turmas daqui em diante, se possível em todos os estágios. Essa prática deveria ser realizada por todos os docentes do Campus Universitário de Bragança, assim poderíamos realizar a tríade (ENSINO - PESQUISA - EXTENSÃO) que tanto é pregada pela Universidade (Patrícia).

No entanto, para que essa tríade ocorra de forma satisfatória como Patrícia almeja, a educação deve estar articulada em seus diferentes níveis, evitando descontinuidade, fragmentação, com vistasa uma ação global, conjunta e que contemple toda a complexidade da situação. Dessa forma, a universidade, como centro de produção do conhecimento, possui grande responsabilidade com a sociedade que a mantém. Essa responsabilidade não está em somente transmitir saberes, mas, sobretudo, com o compromisso de fazer retornar à sociedade o conhecimento produzido na forma de desenvolvimento social, empreendendo ações capazes de contribuir com a transformação de certas condições sociais, políticas, ecológicas, econômicas, visando assim, à melhoria da qualidade de vida da população na qual ela está inserida (GONÇALVES, 2002). 
Nessa mesma perspectiva, as atividades desenvolvidas pelos licenciandos tiveram também a função de intervenção na realidade. Eles puderam perceber como os conhecimentos que utilizam em suas pesquisas podem também ser importantes ferramentas de transformação social, pois não ficaram restritos apenas ao texto do trabalho, mas foram socializados com a comunidade na qual ocorreu a própria coleta de dados da investigação. Foi o que podemos perceber nas falas de duas graduandas, uma que desenvolve sua pesquisa com morfometria de morcegos e outra estudante com ecologia e preservação do caranguejo uça (Ucidescordatus), uma espécie frequente nos mangues dessa região costeira onde se localiza a cidade de Bragança-PA.

- Contudo o que se pode concluir foi que o nosso trabalho com a determinada turma foi proveitoso, pois conseguimos de certa forma mostrar que os animais antes considerados feios e perigosos são de grande importância para o meio em que vivemos e muitas vezes beneficiam a nós mesmos. Dessa forma, os alunos puderam compreender melhor o mundo dessas criaturas e assim levar possivelmente até as suas casas o conhecimento adquirido com a nossa rápida, porém importante apresentação na escola, mostrando que muitas vezes é necessário levar até essas crianças e adolescentes um pouco do que vivemos dentro da universidade (Kely).

- A experiência de levarmos um pouco de nossas pesquisas para dentro de sala de aula nos fez perceber que é possível passar o conhecimento científico a alunos de ensino básico, adaptando àlinguagem e ao cotidiano da maioria deles, assim como incentivá-los àpreservação do meio. De maneira geral, a proposta foi proveitosa e me mostrou que precisamos mostrar nossos resultados e a importância de nossas pesquisas para o ambiente onde vivem e de onde tiram seu sustento, assim como incentivá-los a buscar esse conhecimento (Jussara).

A alfabetização científica promovida por estas ações significa, segundo Chassot (2003), possibilidades para que a população disponha de conhecimentos científicos e tecnológicos necessários para se desenvolver na vida diária, ajudar a resolver os problemas e as necessidades de saúde e sobrevivência básica, como no caso da preservação do caranguejouçá, que é um meio de sustento de comunidades de Bragança, como esta em que foi realizada a ação pedagógica. Compreendemos, assim, que as atividades realizadas na universidade precisam ser analisadas tendo em vista a compreensão das transformações sociais e das suas possíveis influências sobre tais transformações (MARTINS, 2008). O verdadeiro retorno social da extensão se baseia numa busca incessante pela compreensão da realidade social que a comporta e pelapromoção demudanças de certas condições sociais, políticas, ecológicas, econômicas, visando à melhoria da qualidade de vida das populações humanas.

Além disso, nessa interação da universidade com a sociedade, e especificamente com a educação básica, ocorre, de acordo com Dias (2009), a democratização do saber acadêmico e o retorno desse saber à universidade, testado e reelaborado, gerando novas demandas técnicocientíficas, rompendo, dessa forma, com o isolacionismo da transmissão do conhecimento nos diferentes níveis de ensino. Nesse processo de retroalimentação, a extensão é o lugar em que os dados empíricos e teóricos se confrontam gerando permanentes reelaborações, novas demandas técnico-científicas advindas da intervenção na realidade social e direta ou indiretamente a partir das necessidades nelas identificadas.

Essa função imbricada de pesquisa-extensão, que gera novos olhares sobre a pesquisa e novas demandas de estudo, foi percebida pela licencianda Luciana que desenvolveu a aula temática baseada na sua pesquisa sobre educação ambiental empresarial e a Câmara de dirigentes lojistas do município de Bragança-PA. Ela conta sobre a importância dessa divulgação científica para sua formação: 
- Foi uma ideia muito adequada que as professoras tiveram de nos levar a sala de aula pra de certa forma divulgar nossos trabalhos de conclusão de curso ("nossas crias"). Dá mais orgulho e incentivo de fazer o melhor, e também o fato de ter a oportunidade de coletar e perceber alguns pontos que nos ajudarão na pesquisa que estamos desenvolvendo, esse momento na verdade, se torna uma troca de informações que virá a beneficiar todos. Sinto-me muito feliz e grata por ter tido a oportunidade de participar dessa atividade, que foi muito importante para minha formação (Bruna).

Atividades como esta, em que ocorre um processo interativo comunicacional entre os licenciandos e a comunidade escolar, não devem ser vistas só como um ato de difusão científica/tecnológica de mão única, como se somente a universidade pudesse levar conhecimentos.As pessoas da comunidade também têm muitopara ensinar, pois ali há sujeitos que pensam, atuam, refletem sobre a sua realidade, mestra inigualável de grande valor empírico. Assim, ensino-pesquisa-extensão apresentam-se no âmbito das universidades públicas como uma das maiores virtudes e expressão de compromisso social (MARTINS, 2008). Portanto, é importante que os graduandos vivenciem experiências formativas como esta descrita neste trabalho, pois nesse processo eles aprendem a assumir responsabilidades sobre a própria aprendizagem e desenvolvimento pessoal, assim como ampliam a visão de mundo, do seu papel e das suas responsabilidades sociais.

Nesse contexto, a alfabetização científicapode ser considerada como uma das dimensões para potencializar alternativas que privilegiam esse tipo de formação e educação mais comprometida (CHASSOT, 2003). Os reflexos dessa formação podem ser percebidos nos excertos abaixo, em que os licenciandos falam sobre a gratificação em realizar esse trabalho com a comunidade, pois percebem o compromisso que possuem com ela:

- Pude ver nos olhos dela o quanto aquilo que estávamos fazendo era importante para ela e o quanto aquele pequeno esforço da nossa parte em estar ali faria a diferença não só na vida dela, mas de muitas crianças que ali estavam. Fiquei muito contente quando ela falou que estava muito feliz por estarmos na escola dela dando aquela aula, e que queria ir conhecer a Universidade, pois certamente aprenderia muito mais coisas interessantes (Iara).

- Será que serviu de alguma coisa para eles? A simples sensação de poder ajudar ainda que de uma forma esporádica me deixa muito aliviado, pois é por eles que estou aqui na universidade, então é com eles que tenho que prestar contas e isso me faz sentir bem. Além disso, fica a vontade de voltar na escola para fazer um trabalho bem melhor e que mais pessoas sejam alcançadas pela universidade (Yan).

Desta feita, é necessário situar o graduando enquanto sujeito pensante e capaz de articular saberes científicos, pedagógicos e da experiência, no desenvolvimento de uma prática docente coerente. Através de atividades como esta que foi realizada, cria-se oportunidade de praticar o intercâmbio de conhecimentos/experiências entre a universidade e comunidade escolar, na tentativa de romper com o isolacionismo da transmissão do conhecimento e da mesma forma o isolamento da universidade. Nessa direção, é através do compartilhamento de experiências e de saberes específicos, pedagógicos e curriculares no meio escolar, que o licenciando pode elaborar e reelaborar o seu conhecimento trabalhando com conteúdos específicos concretos indissociáveis da realidade social e, através da reflexão e troca de experiências, interferir de alguma forma nesta mesma realidade (SILVA, 2007).

O contato com situações práticas e com as tensões emergidas no contexto educacional e a reflexão, na e sobre a prática desenvolvida, propiciam aos licenciandos e professores, da universidade e da escola, a construção de novos olhares e novas formas de interpretação da realidade escolar e do ser professor na dimensão da sua complexidade e especificidade e da necessidade de uma postura investigativa (MENDES e MUNFORD, 2005; BEBER, FRISON 
e PANSERA 2010). Este processo é fundamental não só para a solução de problemas educacionais de nossas salas de aula, mas também para abrir novos campos de pesquisa sobre problemas reais de nossas escolas em relação às nossas disciplinas e, especificamente,ao ensino de Ciências e Biologia.

\section{IDENTIFICAÇÃO COM A DOCÊNCIA E A REFLEXÃO SOBRE A PRÁTICA}

As ações desenvolvidasnas escolasforam fundamentais para inserção dos graduandos na docência, uma vez que até o momento não tinham tido, em sua maioria, experiências de regência em sala de aula. Nesse sentido, é importante ressaltarmos o quanto é essencial criarmos condições para que a experiência pedagógica do estudante comece o mais cedo possível em seu curso de licenciatura, pois aí os alunos teriam um conteúdo prático para a sua reflexão sobre a prática, associada à teoria em âmbito universitário (GONCALVES e GONCALVES, 1998, p. 116).

Percebemos o quanto os alunos ansiavam pela prática em sala de aula, no sentido de vivenciar esta experiência em todos os sentidos. Portanto, os mesmos puderam planejar, elaborar materiais pedagógicos e reger aulas no ensino fundamental, com apoio das escolas e da universidade, que, por sua vez, deram aporte teórico e estrutural para a realização das práticas. Essas ações foram pontuais, porém bastante significativas, como podemos ressaltar na fala em destaque:

- A experiência e o aprendizado que eu guardo de tudo isso é maravilhosa. Nunca pensei que pudesse me envolver tanto com a escola e os alunos em tão pouco tempo. Eu realmente gostei muito, e me sinto imensamente feliz em ter tido a oportunidade de participar dessa atividade na escola. Poder partilhar com aquelas crianças um pouco do conhecimento que estou construindo foi muito gratificante. $\mathrm{O}$ reconhecimento e agradecimento por tudo isso eu pude ver através dos olhos daquelas crianças (Débora).

Os licenciandos vivenciaram e aprenderam muito mais do que repassar conhecimentos biológicos massivamente, com uma linguagem rebuscada e científica, quase ininteligível para os alunos da educação básica; podemos dizer que esses futuros professores vivenciaram a prática, refletiram sobre a mesma, pesquisaram, discutiram o currículo disciplinar, legitimando a afirmativa de que os estágios supervisionados aparecem como lócus privilegiado de formação, em que a interação universidade-escola tem contribuído para qualificar as licenciaturas, pois é nos processos de interação e vivências com a realidade escolar que o professor se constitui, produz e reelabora saberes docentes necessários à sua formação profissional. Através do compartilhamento de experiências e de saberes específicos, pedagógicos e curriculares no meio escolar, o licenciando pode elaborar e reelaborar o seu conhecimento trabalhando com conteúdos específicos concretos indissociáveis da realidade social e, através da reflexão e troca de experiências, interferir de alguma forma nesta mesma realidade (SILVA, 2007).

Além de tudo isso, é importante destacar que, neste processo, discutimos que o saber da escola não é o saber acadêmico ou o da universidade, é aquele que somado a outros saberes, reelabora-os e tornam-se os saberes da escola (CHASSOT, 2003). Daí a importância e o desafio de traduzir os saberes acadêmicos, produzidos nos laboratórios, em conhecimentos que, somados aos saberes que os alunos trazem consigo - que são tão importantes quanto os científicos- transformam-se, são reelaborados, de forma a contribuir para a formação de cidadãos críticos. 
Entendemos que a experiência vivenciada por nossos alunos, a partir de uma tarefa orientada, foi para muitos deles importante, servindo para fazê-los não apenas pensar sobre a docência, mas também identificar-se com ela. Mariadestaca o quanto foi significativa a experiência docente para ela com as seguintes palavras:

- Uma oficina com o tema Ecologia do Caranguejo-uça, que marcou um momento muito especial na minha vida acadêmica e que foi pouco praticada ao longo do curso. Nessa experiência, trabalhar com uma turma de ensino fundamental foi muito interessante, pois em alguns momentos a vontade de lecionar falou tão alto que eu senti a necessidade de voltar à escola e trabalhar outros temas com as turmas (Maria).

A aluna destaca que a prática docente "foi pouco praticada ao longo do curso",mostrandoquão é essencial que os estágios ocorram para que a docência possa ser vivenciada em todos os seus aspectos e para que os licenciandos possam sentir"a necessidade de voltar à escola e trabalhar outros temas com as turmas". Leonardo, tal como Maria, avalia como tendo sido enriquecedora a experiência com as palavras:

- É gratificante saber que contribuímos com a construção do conhecimento para aquelas crianças. Na verdade isso é o que mais me motiva a ser professor: saber que todo conhecimento adquirido poderá ser passado a outras pessoas para que estes formem seu conhecimento critico acerca do mundo. Sei que a experiência vivenciada não sairá da minha memória e como foi a primeira que tive em uma sala de aula de verdade, tornou-se especial para mim. Gostaria muito que tudo que passei durante pouco menos de três horas naquela sala de aula se repita em todas que entrarei para exercer minha profissão. Sei que não será uma trajetória fácil, mas encararei toda nova turma como um novo desafio a ser superado e, não desistirei, até conseguir perceber que eu faço a diferença na vida dos meus alunos (Leonardo).

Os estágios proporcionam por sua vez a possibilidade de identificação com a docência, pois este contato com as escolas e todo o seu universo escolar incide em reflexões sobre a prática também provocadas pelos professores de estágio, daí a importância dos mesmos em todo este processo. Quando o discente diz "sei que a experiência vivenciada não sairá da minha memória e como foi a primeira que tive em uma sala de aula de verdade, tornou-se especial para mim", evidencia que a experiência foi marcante e decisiva em sua formação inicial. O sujeito assume os riscos da profissão "Sei que não será uma trajetória fácil", mas aceita o desafio com confiança "mas encararei toda nova turma como um novo desafio a ser superado", e ainda se impõe propósitos "e, não desistirei, até conseguir perceber que eu faço a diferença na vida dos meus alunos". Os depoimentos de Beatriz e Sérgio, também enfatizam a importância dessa experiência:

- A realização dessa atividade na escola [...] foi uma oportunidade de percebermos, na prática, o que é ser professor. E apesar de todas as dificuldades, improviso e medo que sentimos, essa experiência vai ser lembrada durante toda nossa vida profissional e pessoal (Beatriz).

- Esse trabalho nos deu a dimensão de como o professor se sente diante de uma sala lotada, onde o mesmo tem que lidar com diversas situações como a que nós encontramos na sala onde ministramos a oficina, onde a professora nos chamou e avisou que na sala teriam duas alunas especiais. E foi então que percebemos que devemos estar preparados para esse tipo de situação e muitas das vezes os nossos professores não estão (Sérgio).

Este processo é fundamental não só para a solução de problemas educacionais de nossas salas de aula, mas também para abrir novos campos de pesquisa a serem estudados sobre problemas reais de nossas escolas em relação às nossas disciplinas e especificamente do ensino de Ciências e Biologia. Como lidar com situações complexas que são inerentes às salas de aulas, já que lidamos com vidas e toda sua complexidade? Como trabalhar com toda a diversidade que naquele ambiente está presente? Ou como nas falas dos licenciandos, como lidar com o "improviso e medo que sentimos?"Como agir nas "diversas situações como a que 
nós encontramos na sala onde ministramos a oficina, onde a professora nos chamou e avisou que na sala teriam duas alunas especiais?".

Diante de todas estas indagações, e outras que possam surgir no âmbito do estágio, o futuro professor precisa ter condições de discutir e questionar, auxiliado por seus professores e colegas, o que concorre para poder se tornar um profissional crítico, conhecendo a realidade e buscando compreender as suas causas (GONÇALVES e GONÇALVES, 1998). Por esse viés, o estágio supervisionado, além de promover a integração entre a prática e os conhecimentos teóricos, através de sua aplicação, reflexão, debate e reelaboração, deve se constituir também como espaço de pesquisa (MENDES e MUNFORD, 2005). Nesse mesmo sentido, Gonçalves (2002) defende a pesquisa na formação de professores para que os professores se tornem pesquisadores de sua própria prática e do contexto social no qual ocorre a docência.

Nessa direção, a ação desenvolvida com os graduandos também oportunizou aos estudantes que refletissem e pesquisassem sua própria prática através dos registros de impressão que elaboraram após a ação. Com esse mesmo propósito, podemos dizer que tanto os graduandos quanto nós, professoras formadoras, realizamos a chamada pesquisa-ação,que é um modelo de pesquisa que possui uma perspectiva de investigação - objetivo de conhecimento - e outra de transformação do contexto em que se trabalha - objetivo prático (GRILLO et al., 2006; GONÇALVES, 2002), uma vez que:

\begin{abstract}
Ela é um tipo de pesquisa social com base empírica que é concebida e realizada em estreita associação com uma ação ou com a resolução de um problema coletivo e no qual os pesquisadores e os participantes representativos da situação ou do problema estão envolvidos de modo cooperativo ou participativo (THIOLLENT, 1986, p. 4 apud GRILLO et al, 2006, p. 5).
\end{abstract}

Por esse viés, torna-se necessário promover discussões dessa prática metodológica no âmbito dos processos de formação inicial e continuada de professores de Ciências e Biologia, a fim de constituir professores reflexivos (FONSECA, VIEIRA e RAMOS 2009). Isto é, professores capazes de problematizar através da reflexão crítica, a realidade pedagógica, analisando e reelaborando, criativamente, os caminhos de sua ação de modo a resolver conflitos, construindo e reconstruindo seu papel no exercício profissional e, assim, ter em vista a transformação de realidades e a formação de cidadãos capazes de olhar seu entorno de modo mais crítico e questionador (BRITO, 2006; GONÇALVES, 2002).

Nesse sentido, a pesquisa-ação privilegia o lugar da extensão universitária, uma vez que promove intervenção, inclusão social - por meio da disseminação de conhecimentos àqueles que têm dificuldade de acesso à Universidade - e mudança de certas condições sociais, políticas, ecológicas, econômicas, visando à melhoria da qualidade de vida das populações humanas, no caso, da população do município bragantino (GONÇALVES, 2002).

Esse processo de interação é extremamente salutar para a educação, particularmente para o ensino de Ciências e Biologia na educação básica, pois a escola passa a ser vista não se constituindo apenas como local físico que abriga a demanda escolar, mas comoum espaço estruturado de produção e de socialização de conhecimento (BEBER, FRISON e PANSERA, 2010), que envolve a todos, mobiliza a escola, como ficou registradoporSara, uma das alunas do curso a desenvolver a ação pedagógica na escola da comunidade de Acarajozinho:

- Houve alunos que perguntaram se iríamos para a sala deles, e a decepção com a negativa me fez realmente desejar ter mais tempo para poder ensinar a todos. A coordenação da escola também gostou do trabalho feito e recebemos diversos convites para retornar. Seria realmente necessária uma parceria da universidade com a escola, pois se tratando de um interior, até mesmo o transporte é difícil de ser conseguido (Sara). 
Nesse sentido, a construção e socialização do saber entre professores da escola, alunos de licenciatura, professores de estágio, e alunos da educação básica, é extremamente importante para todos, pois precisam estar em permanente formação e consciente de que essa formação é imprescindível. Portanto, é necessário que o professor esteja em consonância com a produção do conhecimento acadêmico, refletindo sobre sua prática pedagógica, divulgando suas pesquisas e trabalhando os saberes em conjunto com a escola (DELIZOICOV, 2005), envolvendo e incentivando os seus alunos a pesquisar e construir saberes inéditos, a partir da curiosidade ingênua, de que resulta indiscutivelmente certo saber, o que gera novos dados a serem analisados, refletidos, problematizados, mostrando que, através da dialogicidade, alunos e professores podem, também, no âmbito do ensino, produzir novos conhecimentos (FREIRE, 2006).

Portanto, o conhecimento que é construído e reconstruído contribui diretamente na melhoria da qualidade do Ensino de Ciências realizado no interior das escolas, pois novas leituras vão sendo feitas de acordo com a realidade de cada contexto educacional. Assim, haverá mais retorno, em termos de usos e aplicações, dos resultados de pesquisas em Educação em Ciências e Biologia para alterações significativas das práticas educativas nas escolas, sentidos através da implantação de novas ações na perspectiva de modificação da prática docente, visando à melhoria da educação de nosso país.

\section{CONSIDERAÇÕES FINAIS}

O processo de interação entre universidade e comunidade escolar como o que foi desenvolvido no curso de Ciências Biológicas da UFPA, através da transposição dos conhecimentos científicos das pesquisas acadêmicas para educação escolar básica, é extremamente salutar para a educação, particularmente para o ensino de Ciências e Biologia na educação básica. Dessa forma,a escola passa a ser vista não se constituindo apenas como local físico que abriga a demanda escolar, mas comoum espaço estruturado de produção e de alfabetização científica.

Consideramos, através deste trabalho, que bons resultados pedagógicos são alcançados na medida em que inovações metodológico-curriculares são realizadas a partir da interação Universidade-Escola, em que professores e licenciandos da Universidade e professores da escola interagem ao repensar a prática escolar. A partir desse propósito, as assimetrias de conhecimentos permitem avanços no ensino, no caso do Ensino de Ciências e Biologia, tanto no âmbito escolar quanto acadêmico e na formação profissional de cada sujeito envolvido.

\section{REFERÊNCIAS}

ALARCÃO, I. Professores reflexivos em uma escola reflexiva. São Paulo: Cortez, 2003.

BEBER, L. B. C.; FRISON, M. D. ; PANSERA, M. C. A. Interação Universidade-escola: Produções de Inovação Curricular em Ciências da Natureza e Repercussões na Formação Inicial de Professores de Química. Revista Iberoamericana de Educación, v. 53, p. 1-12, 2010.

BRITO, A. E. O significado da reflexão na prática docente e na produção dos saberes profissionais dos professores. Revista Iberoamericana de Educación, v. 37/8, p. 01-06. 2006.

CATANI, D. B; SOUSA, C. P; VICENTINI, P. P; SILVA, V. B. O que sei de Mim: narrativas autobiográficas, história da educação e procedimentos de formação. IN: Memórias na Educação. 
Programa de pós-graduação em Educação: Universidade Metodista de São Paulo.v.1 n. 1. São Bernardo do Campo: UMESP. 1998.

CHASSOT, A. Alfabetização científica: uma possibilidade para a inclusão social. Revista Brasileira de Educação. n. 22. Jan/Fev/Mar/Abr 2003.

CUNHA, M. I. Conta-me agora! as narrativas como alternativas pedagógicas na pesquisa e no ensino. Rev. Fac. Educ. vol. 23 n. 1-2 São Paulo Jan./Dec. 1997.

DELIZOICOV, D. Resultados da pesquisa em ensino de ciências: comunicação ou extensão? Cad. Bras. Ens. Fís., v. 22, n. 3: p. 364 - 378, dez., 2005.

DIAS, A. M. I. Discutindo caminhos para a indissociabilidade entre ensino, pesquisa e extensão Revista Brasileira de Docência, Ensino e Pesquisa em Educação Física, vol. 1, n. 1, p.37-52. 2009.

FONSECA, M. C.; VIERA, M. M.; RAMOS, M. G. Análise de concepções de professores sobre o significado e a importância da pesquisa na sala de aula. In: Anais do VII Encontro Nacional de Pesquisadores em Educação em Ciências, Florianópolis. 2009.

FREIRE, P. Pedagogia da Autonomia: saberes necessários à prática educativa. São Paulo: Paz e Terra, 1996.

GONÇALVES, T. V. O. ENSINO-PESQUISA-EXTENSÃO: indissociabilidade e inclusão social. In: Atas do I Congresso Brasileiro de Extensão Universitária, João Pessoa. 2002.

GONÇALVES, T. O. \& GONÇALVES, T. V. O. Reflexões sobre uma prática docente situada: buscando novas perspectivas para a formação de professores. IN: GERALD, C. M. G. G, FIORENTINI, D. e PEREIRA, E. M. A. (Orgs). Cartografias do trabalho docente: professor(a) pesquisador(a). Campinas, SP: Mercado das Letras: 1998.

GRILLO, M. C.; ENRICONE, D.; MATTEI, P.; FERREIRA, J. B. Ensino e pesquisa com pesquisa em sala de aula. UNIrevista, vol. 1, n. 2. 2006.

MARTINS, L. M. A indissociabilidade Ensino-Pesquisa-Extensão como um dos fundamentos metodológicos do Ensino Superior. In: ZAMBELLO, S. P. (Org.). Oficinas de Estudos Pedagógicos: reflexões sobre a prática do Ensino Superior. São Paulo: Cultura Acadêmica: UNESP, 2008.

MENDES, R.; MUNFORD, D.Dialogando saberes- pesquisa e prática de ensino na formação de professores de ciências e biologia. Ensaio Pesquisa em Educação em Ciências, vol. 7, n. 3,2005.

MORIN, E. Os sete saberes necessários à educação do futuro. 11 ed. São Paulo: Cortez; Brasília, DF:UNESCO, 2006.

SANTOS, W. L. P.; GAUCHE, R.; MÓL, G. S.; SILVA, R. R.; BAPTISTA, J. A. Formação de professores: uma proposta de pesquisa a partir da reflexão sobre a prática docente. Ensaio. Pesquisa em Educação em Ciências, v. 8, n. 1, p. 1-14. 2006.

SILVA, A. V. Estágio curricular supervisionado no curso de licenciatura: momentos de vivência da profissão professor nas escolas de educação básica. Revista Espaço Acadêmico, n. 73. 2007. 